\title{
The Improvement Study of Knowledge Management in Mount Laojun Scenic in Lijiang
}

\author{
Ding Li and Xiaoqing Li
}

\begin{abstract}
Knowledge management is applied at the scenic area management and used to explore innovative models in travel services management. Knowledge management has a positive meaning to improve service standards and quality. Based on the questionnaire investigation, interview and statistical analysis of staff and tourists in Mount Laojun scenic, there are some relative problems in scenic. Thus several new methods for further planning and development of Mount Laojun in Lijiang are proposed to enhance the competitiveness of the scenic overall.
\end{abstract}

Index Terms-Knowledge management, Mount Laojun in Lijiang, questionnaire survey, scenic.

\section{INTRODUCTION}

In recent years, many scholars have begun to pay attention to the application of knowledge management $(\mathrm{KM})$ in tourism. Marianna Sigala investigates the role of Information and Communication Technologies (ICT) and specifically of the web 2.0 in supporting knowledge management (KM) processes [1]. Jason F. Cohen finds the contingency perspective also received support as the links between KM capabilities and performance were found to be contingent on the business strategy of the firm [2]. Rodrigo Martin-Rojas1 shows mainly that organizational learning best enables hotels to gain from the advent of low cost airlines and the use of information and communication technologies in the company, mainly through the Internet [3]. Flemming Sørensen argues that if tourism service encounters are changed into experience encounters by integrating them into the tourism experience to which they are related, this will create added experiential value for tourists and increase the creation of knowledge about users [4]. Neda T. Farsani indicates that finding, introducing and establishing geosites are the first steps for geopark creation. Furthermore, involving local communities in the conservation of geoparks and providing educational projects are key factors in the knowledge management and preservation of geoparks as new tourist attractions [5]. The findings of Stadler will enable festival managers to better understand how KM processes are embedded within an organizational culture and contribute to organizational learning [2]. L Veldpaus seeks for understanding on how to

Manuscript received March 23, 2015; revised June 20, 2015. The research work was supported by Foundation of Bureau of Science and Technology, Lijiang, Yunnan Provincial under Grant No. 1js2013-09 and scientific research foundation of Tourism and Culture College of Yunnan University under Grant No. 2013xy08.

Ding $\mathrm{Li}$ and Xiaoqing $\mathrm{Li}$ are with the Tourism and Culture College of Yunnan University, 674100, Lijiang, China (e-mail: liding_99@mails.thu.edu.cn,53359058@qq.com). generate research and stimulate knowledge-based management [6]. J Löwstedt gives an account of the process of developing a particular theoretical framework that helps to give a deeper meaning to knowledge management [7]. There are numerous scenic in developed stage now against initial stage several years ago. How to develop the tourism base on ecological environment to pursue the harmonies among nature and culture is what we are concerned. A pattern of tourism based on KM to integrate natural resources, social culture and ecological environment is proposed. This pattern will benefit the future generations. There are some changes taken place in business context of scenic. Especially more and more competitions are increasingly fierce. In this case, the $\mathrm{KM}$ has become an effective way to the scenic spot to win the competitive advantage. More importantly, KM has brought a new pattern of scenic management based on infrastructure of information system and beyond the information centres or professional network management. By studying several empirical and conceptual studies at Mount Laojun geopark in Lijiang, we analyze the state of KM and put forward some corresponding countermeasures to currently existing problems.

\section{OVERVIEW OF KM IN SCENIC}

\section{A. Content and Significance of KM in Scenic}

The content of KM in scenic can be understood from the following several elements. First is explicit knowledge that is shared by all members in spots but it does not form the information that can be understood easily. It does not code to data making exchange knowledge conveniently, too. KM enables scenic knowledge more orderly and logical therefore one can access and master the knowledge at the right time and place in an effective way. The essence of explicit KM is an effective application of existing knowledge on the scenic. Second is tacit knowledge that is saved in the human brain while others hardly obtain which is only directly linked to the unique person. There is no lack of tacit knowledge in the tourism area, which is one of cultural characteristics in the scenic. Knowledge innovations originate from the processes to convert tacit knowledge to explicit knowledge. Innovation can bring new vitality and profit growth to scenic thus new thinking and new products etc. are created to expand the knowledge reserve leading to scenic owning more competitive capability and advantage.

\section{B. Approaches of KM on Scenic Final Stage}

One of the core content of $\mathrm{KM}$ of scenic is the management of human resources. Another is the management of 
information. An environment of shared culture consists of supply chain and knowledge chain to create knowledge that is essential to form an overall network of knowledge. The following are key factors of implementation of KM in scenic: adjusting organizational structure, establishing innovative scenic, constructing network of tourism information, providing knowledge-sharing environment, creating an atmosphere of active knowledge, changing to market in tourism, setting up knowledge alliance among scenic, strengthening knowledge capital management, focusing on the structure of capital accumulation, arranging a chief knowledge officer to ensure normal function of knowledge base in scenic, adhering to the people-oriented strategy, establishing a new incentive mechanism. The role of KM highlights human ingenuity and innovation to maximum. Therefore the use of KM to improve the competitiveness of tourist attractions is the inevitable choice at knowledge economy era. In addition, There are several effects to carry out the KM in the scenic area as following: Mining and inheriting the tacit knowledge of scenic, we can comprehend local residents have long personal experience to local geographical features and cultural atmosphere therefore they can constitute a personalized understanding on their traditions, customs, history and culture. It is difficult to encode it into explicit knowledge. The tacit knowledge was imitated difficultly by another. This is the characteristics which constitute the core competitiveness of the local. Mining such knowledge by KM method will in favor of forming the core competitiveness of tourist attractions. In the process of plan and development to scenic, we advocate the original preservation of local social humanistic amorous feelings nevertheless that does not represent the segregation and imprison policy in modern way of life to local residents. On the contrary, having the option of renewal of knowledge is a necessary means to realize the sustainable development of scenic. We can promote the residents to update their knowledge make them to catch up the current situation of the development scenic spot through KM. Innovation from the KM can bring new vitality and profit growth to scenic making it own more competitive power. Moreover KM make the specification more normalized and rationalize the development and train employees in scenic by a perfect mechanism. We fulfil many innovations on methods of management and marketing, development of goal, business concept by KM.

\section{PRESENT SituAtion OF KM In LAOJUn Mountain}

\section{A. Overview of Laojun Mountain Scenic}

There are more than 1324 square kilometers in Laojun Mountain, Lijiang, Yunnan province, China. It owns rich alpine vegetation, rare animals and plants, many of the glacial lakes and unique Danxia landform .There are many minority nationalities such as Naxi, Bai, Lisu, Pumi, Yi and others live inner this scenic to constitute colourful folk customs thus making it possess very unique landscape and ornamental value and scientific research value . Lijiang Laojun Mountain is continuous stretch and fluctuates for hundreds of miles, layer cascade folds. It consists of four spots: Danxia landform in Liming spot, ninety-nine Longtan spot, Geladan alpine grassland spot, gold silk factory spot. The main peak be called jade peak with golden threads that located the middle of Laojun Mountain. It rose above sea level 4515 meters. Ancient historians called it the ancestor of all mountains in Yunnan province. As one of the world natural heritage, Lijiang Laojun Mountain is one of eight major scenic area of three rivers flow parallel.

\section{B. Data Sources}

The present management situations of Lijiang Laojun Mountain scenic are studied by questionnaire survey. A total of 80 questionnaires were distributed, 79 were recovered, 79 effective questionnaires, the questionnaire recovery rate was 98.75\%.In the investigation of the crowd senior managers accounted for $3.4 \%, 22.4 \%$ middle managers, general managers $14.7 \%$, grass-roots staff accounted for the main, 59.5\%. After finishing the analysis, we can see that the present knowledge management situation in Laojun Mountain scenic spot.

\section{A Preliminary Survey to Tourists and Staff}

With the development of computer, network and other infrastructure gradually entering the scenic area, the explicit knowledge management of scenic area is becoming more perfect. To establish an intranet in scenic is so important that finishing data collected and knowledge compiled timely and transmitted conveniently will greatly improve work efficiency. In addition, there are diverse channels for tourist to know the situations of scenic. Through survey we find percentage constitutes of all tourist as follow: to know Mount Laojun by friends or relatives is $32.5 \%$, by promo of travel agents is $27.5 \%$, by internet is $13 \%$, by TV station is $11 \%$, by newspaper is $5 \%$, by journal is $4 \%$, the rest is $7 \%$.One of the options in questionnaire to the scenic staff is "Do you think the currently available information and shared knowledge can support your work effectively?". We use of scoring methods: "very satisfied" with 10 points, " satisfied " 8 points, "general satisfied " six points, "unsatisfied" four points and "very dissatisfied" 2 points. The comprehensive score is 6.4 points just higher than the pass line (6 points). The other option is "What is the major barrier in knowledge and information shared when you encounter in your work? " There are 35\% staff choose that this scenic lack information technology support. These data shows that the construction of network and shared information in scenic need to be further strengthened.

\section{Existing Insulated Island of Knowledge Data Sources}

As a scenic spot, whether it belongs to natural or man-made landscapes it must has certain cultural background thus it can attract tourists effectively. In the questionnaire " The Laojun Mountain scenic area planning activities reflect the local cultural characteristics", the option "consent" chosen account for less than $40 \%$, neutral is more than 30 percent, the sum of disagree and strongly disagree is less than $30 \%$. Obviously, these planning activities basically reflect the characteristics of the local ethnic culture. Some ethnic characteristics of the activities and practices have been excavated to the scenic to perform at the national cultural centre by music and dance to 
reflect the customs, lifestyles and production of the minorities such as Lisu, Naxi and others to express their enthusiastic love to life. What especially valuable is that visitors can participate in passion to these magnificent, popular dance and enjoy the unique charm of minorities all these to form the distinctive cultural characteristics of Mount Laojun thus have strong attractions for tourists. Many residents possessing local life and customs are also actively involved in the construction of scenic and they provide the capital of tacit knowledge that has been fundamental importance to scenic. we conducted by scoring the option "very good" is 10 points, "better" is eight points, "unclear" is six points, "bad" is 4 points, "very bad" is 2 points. In investigation of the degree of collaborations between Mount Laojun and other travel companies; the degree of collaborations among respective department inner Mount Laojun, the calculated results as follows: the former is 5.8 points and the latter is 5.9 points both are lower than the pass line 6 points that indicating the environment of collaboration inside and outside scenic Mount Laojun needs to be strengthened. There are insulated islands of knowledge existing insides respective department in scenic and other tourism enterprises. This phenomenon will hinder the sharing of information and knowledge, which will damage to the overall efficiency and waste of resources in scenic.

\section{E. Scenic Lack Sound Management and Effective Incentive Mechanism}

Questionnaire analysis showed that the staffs of Laojun Mountain scored the currently working environment 6.85 points. In the analysis of the causes, we find the staffs give high points to leader that indicating there are harmonious relationships between subordinate managers and staffs. But in terms of development opportunities, staff give relatively low valuation only 5.7 points that indicating little opportunity for promotion of employees. In "Have you made a constructive suggestion to your boss?"there are more than $27 \%$ of people said they had never given any suggestions to their managers, more than $22 \%$ of people said they had given some suggestions but no reaction in managers, only $18 \%$ of people views was adopted. These data show that scenic lack management in an effectively incentive mechanism, therefore deteriorate the atmosphere of organizational learning and cultural innovation. The employees of scenic often get all kinds of knowledge and information through mutual exchange rather than internal electronic documentation system. Nearly $23 \%$ of the staffs have never used it. In the process acquiring knowledge and information, the probabilities of various channels that staff acquiring knowledge and information are about $33 \%$ on average. In terms of innovation, the development of Laojun mountain scenic area in recent years largely depends on its advantage in traditional tourism resources and high profile. This is a monopoly of resource products having important fundamental of competitiveness in the beginning but lacking a certain product innovation and competitiveness in the long run, which does not favors the continuation of life cycle in Laojun Mountain scenic.

\section{KM STRATEGIES IN SCENIC OF MOUNT LAOJUN}

There are some difficulties to implement further knowledge management in Scenic of Mount Laojun, especially those spots are located in a remote area and lacked technical support from the status quo of view. Maybe we can gradually improve it in the future development. Tourism practitioners, especially scenic managers should be fully aware of the importance of knowledge management. According to the actual situation of the scenic spot of Laojun to implement knowledge management, the following several aspects of the improvement suggestions are put forward.

\section{A. Setting the Department in Charge of Knowledge and Innovation}

It is necessary to set up specialized knowledge management department in regulatory bodies in scenic. This department is responsible for collecting and collating resources closely related to local history, culture and natural. The department is also responsible for the following functions: training the local tourism practitioners; constructing and maintaining tourism management information system; participating the establishment of long-term planning and the rules and regulations in scenic; obtaining the latest international tourism information; arranging and analyzing the feedback from tourists and tourism practitioners. In brief, this department can coordinate the interests and relationship among various stakeholders and ensure smooth operation of knowledge management.

\section{B. Establishing a Flat Organizational Structure of the Scenic Spot}

There are too many organizational levels inner the traditional scenic spot to lead many shortcomings e.g. distortion of information, loss of opportunities, barriers to communication and exchange, lack of vitality and resilience etc. Therefore the scenic must have a flexible response ability to adjust constantly according to real situations. The managers should strengthen the exchanges and cooperation among departments so that every employee is able to access information, share knowledge, to participate in decision-making letting scenic to take on the characteristic of knowledge and respond to market changes properly.

\section{Establish Mutual Alliance of Knowledge among Tourist Attractions}

There are more characteristics of the regional economy in tourism economy. The economic benefits of one scenic spot are closely related to its surrounding scenic. The information-sharing mechanism should be established with surrounding tourist attractions to exchange and share related resources through the complementary advantages among each other to determine whether making tourist together to a group or divided it to several groups. At the same time, through information interaction administrative staff can also coordinate the characteristic construction of local scenic to distinguish each other and avoid duplicate construction seeking win-win in the competition and cooperation to promote development in harmonious ways.

\section{CONCLUSIONS}

With the development of tourist attractions in the future, 
the use of knowledge management to improve the competitiveness in tourist attractions will be the inevitable choice in knowledge economy era. In this paper, we choose Mount Laojun in Lijiang as a typical example of scenic to investigate and analyze the knowledge management status quo, indicating the construction of information is gradually strengthened and explicit knowledge management is maturing step by step while there are some problems existing: lacking the source of innovation and attention to excavate tacit knowledge and existing the insulated island of knowledge. Some solutions were put forward from human resource management, organizational structure, and innovation etc. points of view.

\section{REFERENCES}

[1] M. Sigala and K. Chalkiti, "Investigating the exploitation of web 2.0 for knowledge management in the Greek tourism industry: An utilisation-importance analysis," Computers in Human Behavior, vol. 30, pp. 800-812, 2014.

[2] J. F. Cohen and K. Olsen, "Knowledge management capabilities and firm performance: A test of universalistic, contingency and complementarity perspectives," Expert Systems with Applications, vol 42, no. 3, pp. 1178-1188, 2015.

[3] R. Martin-Rojas, V. J. Garcia-Morales, and A. Mihi-Ramirez, "Knowledge-based organization in tourism industry," Engineering Economics, vol. 25, no. 1, pp. 82-93, 2014.
[4] J. Mattsson, F. Sørensen, and S. Barnes, "Value creation and knowledge development in tourism experience encounters," Annals of Tourism Research, 2014.

[5] N. T. Farsani, C. O. Coelho, C. M. Costa, and A. Amrikazemi, "Geo-knowledge management and geoconservation via geoparks and Geotourism," Geoheritage, pp. 1-8, 2014.

[6] L. Veldpaus, "Book review: Perspectives on archaeological heritage management," Journal of Cultural Heritage Management and Sustainable Development, vol. 4, no. 1, 2014.

[7] J. Löwstedt and T. Stjernberg, Producing Management Knowledge: Research as Practice, Routledge, 2014.

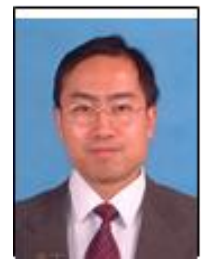

Ding Li was born in 1980, Chongqing, China. He received the M.Sc. degree from Yunnan University, China in 2011. He is currently a lecturer in Department of Information Science, Tourism and Culture College of Yunnan University. His research interest is in the area of network data mining.

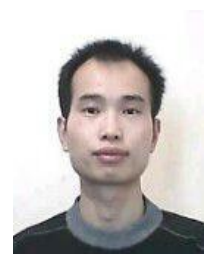

Xiaoqing Li was born in 1979, Hunan, China. He received the M.A. degree from Central South University, China in 2009, English major. He is currently a lecturer in Tourism and Culture College of Yunnan University. His research interest is in the area of semantic analysis. 